\title{
Help-seeking in people with exceptional experiences: results from a general population sample
}

\section{Karin Landolt ${ }^{1,2}$, Amrei Wittwer ${ }^{2}$,Thomas Wyss ${ }^{2}$, Lui Unterassner ${ }^{2}$, Wolfgang Fach $^{3}$, Peter Krummenacher ${ }^{2,4}$, Peter Brugger ${ }^{5}$, Helene Haker ${ }^{2,6,7}$, Wolfram KawohI ${ }^{8}$, Pius August Schubiger ${ }^{2}$, Gerd Folkers ${ }^{2}$ and Wulf Rössler ${ }^{1,2,9,10 *}$}

\author{
1 Department of Psychiatry, Psychotherapy and Psychosomatics, Zürich University Hospital for Psychiatry, Zurich, Switzerland \\ 2 Collegium Helveticum, Zurich, Switzerland \\ ${ }^{3}$ Institute for Frontier Areas of Psychology and Mental Health, Freiburg, Germany \\ ${ }^{4}$ Department of Psychology, Clinical Psychology and Psychotherapy, University of Basel, Basel, Switzerland \\ ${ }^{5}$ Department of Neurology, University Hospital Zurich, Zurich, Switzerland \\ ${ }^{6}$ Translational Neuromodeling Unit (TNU), Institute for Biomedical Engineering, University of Zurich, Zurich, Switzerland \\ 7 Translational Neuromodeling Unit (TNU), Institute for Biomedical Engineering, ETH Zurich, Zurich, Switzerland \\ ${ }^{8}$ Department of Psychiatry, Psychotherapy and Psychosomatics, Center for Social Psychiatry, Zürich University Hospital for Psychiatry, Zurich, Switzerland \\ ${ }^{9}$ Leuphana University, Lüneburg, Germany \\ ${ }^{10}$ Laboratory of Neuroscience (LIM27), Institute of Psychiatry, University of São Paulo, São Paulo, Brazil
}

Edited by:

Alexandre Andrade Loch, University of São Paulo, Brazil

Reviewed by:

Aikaterini Arvaniti, Democritus University of Thrace, Greece

Luís Fernando Tófoli, University of

Campinas, Brazil

Rafael Teixeira De Sousa, University

of São Paulo, Brazil

\section{*Correspondence.}

Wulf Rössler, Department of

Psychiatry, Psychotherapy and

Psychosomatics, Zürich University

Hospital for Psychiatry, Militärstrasse

8, Postfach 1930, Zurich 8021 ,

Switzerland

e-mail: roessler@dgsp.uzh.ch
Background: Exceptional experiences (EE) are experiences that deviate from ordinary experiences, for example precognition, supernatural appearances, or déjà vues. In spite of the high frequency of EE in the general population, little is known about their effect on mental health and about the way people cope with EE. This study aimed to assess the quality and quantity of $E E$ in persons from the Swiss general population, to identify the predictors of their help-seeking, and to determine how many of them approach the mental health system.

Methods: An on-line survey was used to evaluate a quota sample of 1580 persons representing the Swiss general population with respect to gender, age, and level of education. Multinomial logistic regression was applied to integrate help-seeking, self-reported mental disorder, and other variables in a statistical model designed to identify predictors of help-seeking in persons with $\mathrm{EE}$.

Results: Almost all participants (91\%) experienced at least one EE. Generally, help-seeking was more frequent when the EE were of negative valence. Help-seeking because of EE was less frequent in persons without a self-reported mental disorder (8.6\%) than in persons with a disorder (35.1\%) (OR=5.7). Even when frequency and attributes of EE were controlled for, people without a disorder sought four times less often help because of EE than expected. Persons with a self-reported diagnosis of mental disorder preferred seeing a mental health professional. Multinomial regression revealed a preference for healers in women with less education, who described themselves as believing and also having had more impressive EE.

Conclusion: Persons with EE who do not indicate a mental disorder less often sought help because of $E E$ than persons who indicated a mental disorder. We attribute this imbalance to a high inhibition threshold to seek professional help. Moreover, especially less educated women did not approach the mental health care system as often as other persons with EE, but preferred seeing a healer.

Keywords: psychiatric disorder, exceptional experiences, help-seeking, public health, epidemiology

\section{INTRODUCTION}

Exceptional or extra-ordinary experiences (EE) are frequent in the population, with the prevalence being estimated at $30 \%-$ $75 \%(1,2)$. Most people have at least once in their life had $\mathrm{EE}$, like hearing the voices of dead loved ones, precognition, supernatural appearances, or déjà vues. In spite of the high frequency, little is known about their effect on mental health and about the way people cope with EE. Although EE are fascinating, EE with a high negative valence can cause subjective suffering (3), and EE and magical ideation (MI) are conceptually close to psychosis $(4,5)$. When EE are successfully coped with, they can add to psychological health (3). This indicates that people who are not able to cope with their EE could benefit from easy accessible and professional help. The skills of 
health professionals and healers in dealing with $\mathrm{EE}$ are yet to be evaluated.

Exceptional experiences do not fit yet into the psychopathological classification systems, because the exact interrelation between mental disorders and EE is not known yet. Our definition of EE aims to encompass a wide spectrum of experiences: EE are usually understood to deviate from or being at variance with ordinary experiences, as defined by typical "reality models" (6) that have been adopted by individuals to fit within their own socio-cultural environment $(3,7)$. In modern societies, such models are largely based on well-founded epistemological concepts (e.g., cause-andeffect relations) and established scientific principles or laws (e.g., gravity). This coarse characterization covers four broad types of phenomena: (1) external phenomenon, such as apparitions, which reflect the environment of an individual, i.e., the "world" model; (2) internal phenomenon, such as invasive thoughts, i.e., the "self" model (6); (3) dissociation phenomenon, which can occur due to deviations in the relations between the "world-model" and "self-model," such as out-of-body experiences; or (4) coincidence phenomenon, including extrasensory perceptions $(7,8)$. For individuals undergoing those experiences, the phenomenological typology of EE, which has been strongly inspired by Metzinger's representational approach within the philosophy of mind (6), is neutral with respect to their consequences. This means that each type of EE can have positive and negative consequences, for example, the quality of life may either decline or improve, individuals may suffer or profit because of them, and those experiences may or may not belong to a category of mental (psychiatric) disorders. This last differentiation is important because symptoms of mental disorders and EE can be quite similar.

Exceptional experiences must be systematically distinguished from the belief in such experiences, e.g., MI (9). Although experiences and beliefs are correlated, individuals with strong beliefs in non-causal influences or unknown physical forces (10) do not necessarily report EE and vice versa. An important distinction between the two is that experiences have more state character while beliefs are predominantly traits. Although there may be trait-like dispositions for EE, they are currently unknown. It is also far from well-established that beliefs show a one-to-one relationship with such dispositions.

Considering EE, the distinction between illness and health seems difficult. It is not yet clear whether EE are part of the subclinical end of the psychosis spectrum (11-13), or whether they belong to another category of phenomena. How EE can be separated from or are interrelated with schizotypal signs as described by Johns and van Os (11) remains unclear yet. Both EE and magical beliefs have found to be associated with phases of mental disorder (9, $14,15)$. However, neither do all persons who report EE also suffer from mental disorders, nor are all experiences unpleasant. A recent continuum hypothesis (11-13) has postulated a gradual change between mental health and disorder, which has been argued to be more plausible than a discrete, absolute assignment to just one of those two categories. According to this hypothesis, it is self-evident that many EE are not indicators of mental disorders, at least when they are few. Results from neurophysiological evaluations have supported this continuum hypothesis. For example, dopaminergic hyperactivity and increased dopamine availability seem to be involved along the entire schizophrenia spectrum (16-20), and both also coincide with high scores in MI (21). Furthermore, MI might have some health-promoting aspects, helping a person cope with life events (3) or high dopamine levels (21). The performance in perceptual cognitive sensitivity judgments of healthy persons scoring high in MI was unaffected by an experimentally induced dopamine challenge. By contrast, low MI persons' sensitivity decreased under the influence of a dopamine agonist. Moreover, with respect to their response behavior, low-scoring MI persons became less and high MI scorer more conservative under increased dopamine levels (21).

Up to our knowledge, there is no study examining whether and how often persons suffering from EE seek help, and how many of them approach the mental health system. A report by Hellmeister and Fach (22) for a committee of inquiry of the German government has described the complicated structures of motivations that compel help-seekers to approach unprofessional healers. It is important that the help given to people with $\mathrm{EE}$ is adequate, because the valence and interpretation of the EE could determine - among other things - whether EE can add to psychological health (3).

The way in which persons reporting EE seek help has up to now mostly been considered from the perspective of mental disorders. However, to infer a close interrelation seems to be premature, as the only systematic study known to cover this issue so far (3) concluded that persons seeking assistance because of EE did not necessarily suffer from mental disorder. Help-seeking caused by mental disorders has been analyzed extensively in large studies (23-25) that have found that only about $25-33 \%$ of individuals diagnosed with a mental disorder receive professional treatment. The most consistent predictor for help-seeking across different syndromes has been "subjective suffering" due to the disorder (26).

The aims of this study were to explore the quality and quantity of EE in the general population, to identify predictors of helpseeking because of $\mathrm{EE}$, and to determine when the mental health care system is involved.

\section{MATERIALS AND METHODS \\ SAMPLE}

The sample of persons who received the on-line questionnaires represented the Swiss population in terms of gender, age, and education. Subjects were part of a pool from two professional recruiters, panelbiz ${ }^{1}$ and respondi ${ }^{2}$. The first recruiter provided a group of about 45,000 persons, from which a stratified quota sample of about 5000 persons was selected and asked for participation. Because this quota was incomplete, more persons were added from the pool of the first recruiter as well as others from the second recruiter. The individuals were initially invited with a standardtext email message containing formalities and technical details. Afterward, the on-line questions required approximately $15 \mathrm{~min}$ to answer, for which the participants received 5 Swiss Franks (4.1 Euro) as small compensation. The study was approved by the local ethics committee ${ }^{3}$.

\footnotetext{
${ }^{1}$ www.panelbiz.ch

${ }^{2}$ www.respondi.com

${ }^{3}$ Kantonale Ethikkommission Zürich, www.kek.zh.ch
} 


\section{INSTRUMENTS}

Inquiries about EE were made via the PAGE-R (27), a revised and condensed version of PAGE (Fragebogen zur Erfassung der Phänomenologie Aussergewöhnlicher Erfahrungen/Questionnaire for the Assessment of the Phenomenology of EE) $(28,29)$ [for more details see Ref. $(29,30)]$. The PAGE, created by the Institute for Frontier Areas of Psychology and Mental Health (IGPP), characterizes the phenomenology of EE according to the phenomenological classification indicated above. The revised version applied in this study had been developed recently, and can be used with on-line studies. The four factors in PAGE-R included external phenomenon (eight items), internal phenomenon (eight items), phenomenon of coincidence (eight items), and psychophysical dissociation (eight items). Possible answers were $0=$ "never," $1=$ "rarely," 2 = "sometimes," $3=$ "often," or $4=$ "very often." Mean scores for these were calculated (Cronbach's alpha $=0.886,0.881,0.895$, and 0.884, respectively). Each section was supplemented by questions specifying when the phenomenon had occurred (during the last 12 months, last 5 years, last 10 years, longer ago than 10 years, or before the age of 18), as well as one question that assessed whether the person had been concerned with such a phenomenon up until now $(0=$ "not at all," 1 = "a little," 2 = "partly," 3 = "fairly," or 4 = "very"). Questions addressing the impact of the phenomenon were combined on one scale representing overall mean impact, and the questions on the location of the experiences within the person's lifespan were combined on one scale representing the "density" of EE. The PAGE-R concluded with 14 items ( $0=$ "not at all," $1=$ "a little," $2=$ "partly," $3=$ "fairly," or 4 = "very") specifying the circumstances (e.g., spontaneous, against one's will) and causes (e.g., following life events, following contact with healer) of those experiences. A factor analysis $^{4}$ of the 14 items yielded three factors - "experiences caused by spiritual techniques, esoteric practices, or contact with healers" (7 items, Cronbach's alpha $=0.771$ ); "experiences with negative valence" (7 items, Cronbach's alpha $=0.759$ ); and "spontaneous experiences with rather positive valence" (4 items, Cronbach's alpha $=0.746$ ), all of which were used in the analyses. At the end of the PAGE-R, two questions ${ }^{5}$ on help-seeking were added that differentiated among seeing either a healer, shaman, or psychic (further referred to as healers), or else a psychiatrist, psychotherapist, or psychologist. In addition, questions were asked about the socio-demographical attributes and diagnoses of mental disorders for the subject himself/herself and persons in his/her family. This included a preliminary question (yes/no/no answer) followed by an open question about the exact name of the disorder. The participants' answers were classified as exactly as possible into broad categories.

Magical ideation was assessed via the MI (9) questionnaire. The individual degree of "vulnerability" for believing in MI can lead to a distinction between "sheep" (believers) and "goats" (skeptics)

\footnotetext{
${ }^{4}$ Principal Component Analysis, Varimax-Rotation with Kaiser-Normalisation, converged in six iterations; factor-loadings of variables were interpreted when higher than 0.3 .

${ }^{5}$ (a) "(those experiences) led me to seek help from a psychiatrist, psychotherapist, or psychologist" (yes/no). (b) "(those experiences) led me to seek help from a shaman, healer, or psychic" (yes/no).
}

(31). Moreover, the two classes differ with regard to their success in experimental studies that have focused on extrasensory perception (31-33), associative tasks, semantic priming, and other cognitive processes (21,34-37). The broadly used MI encompasses 30 items that can be answered with "yes" or "no." After the MI scores were summed here (Cronbach's alpha $=0.808$ ), the median value was used to differentiate between "skeptics" and "believers."

\section{STATISTICAL ANALYSES}

Statistical analyses comprised two steps. First, any possible predictors of help-seeking were examined, using bivariate significance testing with a dependent variable that differentiated among seeing a healer, mental health professional, or both. Second, the bivariate significant variables were combined into one model that used multinomial logistic regression analysis to identify the strongest predictors of help-seeking. Analyses were performed with SPSS/PASW Statistics 18.

\section{RESULTS}

The final sample consisted of 1580 persons. Of the 32 cells in the quota table, 18 were entirely filled; the mean deviance from the desired number was $7.0 \%$. The mean age was 39.1 years and $51.6 \%$ of the participants were women. In the education category, $11.5 \%$ (181) had completed compulsory school, 43.4\% (686) received vocational training, $11.2 \%$ (177) had a high school diploma, and $33.9 \%$ (536) had finished university or another type of higher education (Table 2 ).

In total, 100 participants $(7.4 \%$ of the 1353 participants who answered the questions on help-seeking) had asked for assistance from a healer, shaman, or psychic ("healer"), and 109 participants $(8.1 \%)$ had sought help from a psychiatrist, psychotherapist, or psychologist ("mental health professional"). Of the participants answering the questions on help-seeking, 5.5\% had seen only a healer, $1.8 \%$ saw both healer and mental health professional, $6.2 \%$ preferred a mental health professional, and $86.4 \%$ did not seek help because of their experiences. The rate of self-indicated actual and/or past diagnosis of mental disorder was $16.1 \%(3.2 \%$ no answer), while $22.2 \%$ (3.9\% no answer) had indicated a history of psychiatric disorder(s) in the family. Table 1 shows the categories of diagnoses specified by the participants.

Depression and anxiety disorders were the most frequently mentioned by the participants themselves, followed by burnout, bipolar disorder, borderline personality, ADHD, and substance use (Table 1). Within the family, the most frequent disorder was depression followed by schizophrenia. The latter was reported at a quite frequent rate of $2.8 \%$.

Indicating a mental disorder (current or past) coincided with a tendency to visit both a healer and a mental health professional, or else a mental health professional alone, but not a healer alone (Figure 1). Persons with diagnosis had more often sought help (35.1\%) than persons without $(8.6 \%)$.

Of all the participants, the majority reported having at least one EE during their lifetime. A "no" answer was given by 141 persons $(8.9 \%)$ to all PAGE-R items about EE. Approximately $25 \%$ denied all items from Class 1 "external phenomenon" and Class 2 "internal phenomenon," whereas about $20 \%$ acknowledged experiencing Class 3 "phenomenon of coincidence" and 50\% were in 
Table 1 | Self-reported diagnoses of participants

\begin{tabular}{|c|c|c|c|c|}
\hline & \multicolumn{2}{|c|}{ Self } & \multicolumn{2}{|c|}{ Family } \\
\hline & $N$ & $\%$ & $N$ & $\%$ \\
\hline No & 1257 & 80.7 & 1169 & 74.0 \\
\hline No answer & 50 & 3.2 & 61 & 3.9 \\
\hline None indicated & 50 & 3.2 & 13 & 0.8 \\
\hline Depression & 121 & 7.7 & 212 & 13.4 \\
\hline Anxiety disorders & 29 & 1.8 & 11 & 0.7 \\
\hline Burnout & 23 & 1.5 & 18 & 1.1 \\
\hline Bipolar disorder & 8 & 0.5 & 12 & 0.8 \\
\hline Borderline personality disorder & 8 & 0.5 & 6 & 0.4 \\
\hline ADHS & 7 & 0.4 & 7 & 0.4 \\
\hline Substance misuse/dependence & 7 & 0.4 & 6 & 0.4 \\
\hline Trauma/PTSD & 4 & 0.3 & 0 & 0.0 \\
\hline Obsessive compulsive disorder & 3 & 0.2 & 3 & 0.2 \\
\hline Somatoform/developmental disorder & 3 & 0.2 & 5 & 0.3 \\
\hline Schizophrenia & 2 & 0.1 & 45 & 2.8 \\
\hline Various, does not know name & 2 & 0.1 & 9 & 0.6 \\
\hline Dementia & 0 & 0.0 & 7 & 0.4 \\
\hline Others & 16 & 1.0 & 26 & 1.6 \\
\hline
\end{tabular}

Psychiatric diagnoses indicated by the participants themselves, categorized along the main disorders. Multiple responses were possible.

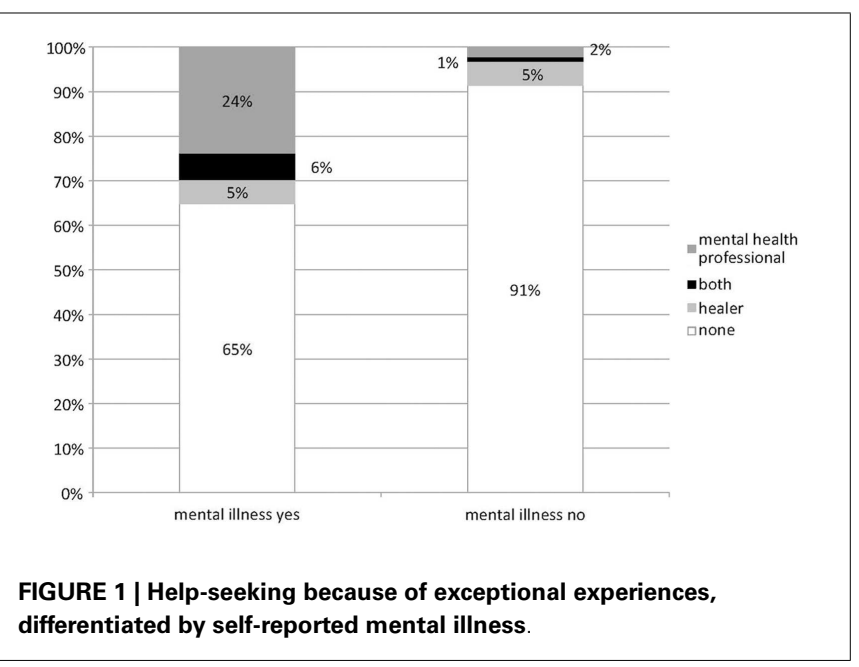

Class 4 "psychophysical dissociation." Experiences within Classes 1 and 2 (mean 0.76) were rated as less frequent than within Class 3 (0.96) but more frequent than Class $4(0.55)$. The mean impact was quite low (between "not at all" and "a little"), and most phenomena occurred during only one phase of life $($ mean $=1.14)$ (Table 3). MI was also quite frequent. According to the MI, only 11 participants answered all questions with "no." The median was 9 positive answers (maximum 25) - individuals above that were classified as believers, those below as skeptics (Table 2 ).

Tables 2 and 3 indicate the bivariate associations between predictors and help-seeking. Significant interrelations were found for education, marital status, living alone, occupation, believing, (history of) psychiatric diagnosis for self or family, MI skeptics and believers, and all PAGE-R indicators.

Table 4 presents the bivariately significant predictors in a multinomial regression with the dependent variable, combining both healer and mental health professional.

Help-seeking was predicted by the additional attributes of EE rather than by the classes of experiences measured by the PAGE$\mathrm{R}$ questionnaire. When experiences were induced by (spiritual) techniques, and when they had more impact, individuals were more likely to visit a healer or both a healer and a mental health professional. Seeing the latter or both was predicted only by diagnosis. Negative valence triggered help-seeking in general. Skeptics, as determined via the MI, sought help less often from a healer alone.

Some socio-demographical variables clearly predicted helpseeking behavior in the combined model. For example, compared with men, women visited more often a healer alone but less often both a healer and mental health professional. Believing in a deity/less education also were associated with help-seeking from a healer alone. Persons who were not employed visited both more often.

Table 5 illustrates that persons with a self-reported diagnosis of mental disorder four times more often sought help, even when all characteristics of EE were controlled for. The relation between mental disorder and help-seeking remained highly significant in the model with number of different $\mathrm{EE}$, mean frequency of EE, frequency over the life course (density), additional characteristics of EE, and mean burden caused by the EE.

\section{DISCUSSION}

In this sample from the Swiss general population, almost all participants $(91 \%)$ indicated having had at least one exceptional experience. The typology of EE did not correlate with self-reported mental disorder. This was rather unexpected, because an earlier study had shown that persons with an internal phenomenon have contact with the psychiatric field more often (3). The rate of EE-induced help-seeking was $13.6 \%$ among the persons with at least one EE. About $8.1 \%$ thereof visited a mental health professional, 7.4\% approached a healer. Help-seeking because of EE was globally associated with negative valence of EE. Help-seeking was less frequent in persons without a self-reported mental disorder $(8.6 \%)$ than in persons with such a disorder $(35.1 \%)(\mathrm{OR}=5.7)$. But interestingly, even when the frequency, the valence, and other attributes of EE were controlled for, people without a disorder sought four times less often help because of $\mathrm{EE}$ than persons with a disorder $(\mathrm{OR}=4.5)$. Self-reported mental disorder was highly correlated with the rate of EE-induced help-seeking in the mental health care system, but not with alternative sources of help: independent of mental disorder, about $5 \%$ of the participants visited healers, shamans, or psychics because of EE. Multinomial regression revealed a preference for healers in women with less education, who described themselves as believing (according to a global question and according to the MI) and also having had more impressive EE. Other predictors of help-seeking besides gender and education were occupation and the trigger of the experienced EE. 
Table 2 | Categorical predictors of lifetime help-seeking because of EE ( $N$ depending on variable).

\begin{tabular}{|c|c|c|c|c|c|c|}
\hline & \multicolumn{2}{|c|}{ Total } & \multicolumn{2}{|c|}{ Healer } & \multicolumn{2}{|c|}{ Psychiatrist } \\
\hline & $N$ & $\%$ & $N$ & $\%$ & $N$ & $\%$ \\
\hline Total & 1580 & 100 & 100 & 7.4 & 109 & 8.1 \\
\hline \multicolumn{7}{|l|}{ Gender } \\
\hline Woman & 816 & 51.6 & 59 & 8.2 & 52 & 7.3 \\
\hline Man & 764 & 48.4 & 41 & 6.4 & 57 & 8.9 \\
\hline \multicolumn{7}{|l|}{ Education } \\
\hline Compulsory school & 181 & 11.5 & 24 & 15.5 & 22 & 14.2 \\
\hline Vocational training/school & 686 & 43.4 & 38 & 6.6 & 48 & 8.4 \\
\hline Secondary school & 177 & 11.2 & 14 & 8.8 & 6 & 3.8 \\
\hline University/higher education & 536 & 33.9 & 24 & 5.2 & 33 & 7.1 \\
\hline \multicolumn{7}{|l|}{ Marital status } \\
\hline Unmarried & 644 & 40.8 & 37 & 6.6 & 36 & 8.2 \\
\hline Married & 694 & 43.9 & 36 & 6.1 & 48 & 6.5 \\
\hline Divorced & 225 & 14.2 & 23 & 12.2 & 22 & 11.7 \\
\hline Widowed & 17 & 1.1 & 4 & 28.6 & 3 & 21.4 \\
\hline \multicolumn{7}{|l|}{ Partner } \\
\hline No & 436 & 27.6 & 32 & 8.6 & 35 & 9.4 \\
\hline Yes & 1144 & 72.4 & 68 & 6.9 & 74 & 7.5 \\
\hline \multicolumn{7}{|l|}{ Children } \\
\hline No & 745 & 47.2 & 46 & 7.2 & 50 & 7.8 \\
\hline Yes & 835 & 52.8 & 54 & 7.6 & 59 & 8.3 \\
\hline \multicolumn{7}{|l|}{ Living alone } \\
\hline No & 1087 & 68.8 & 59 & 6.3 & 66 & 7.0 \\
\hline Yes & 493 & 31.2 & 41 & 9.9 & 43 & 10.4 \\
\hline \multicolumn{7}{|l|}{ Occupation } \\
\hline School & 123 & 7.8 & 4 & 3.8 & 6 & 5.7 \\
\hline Employed & 1173 & 74.2 & 74 & 7.5 & 67 & 6.8 \\
\hline Domestic work & 224 & 14.2 & 12 & 6.0 & 18 & 9.0 \\
\hline Pensioner & 60 & 3.8 & 10 & 12.7 & 18 & 31.0 \\
\hline \multicolumn{7}{|l|}{ Cultural background } \\
\hline Middle Europe & 1469 & 93.0 & 90 & 7.1 & 100 & 7.9 \\
\hline Other & 111 & 7.0 & 10 & 10.0 & 9 & 10.2 \\
\hline \multicolumn{7}{|l|}{ Denomination } \\
\hline Protestant & 504 & 31.9 & 23 & 5.3 & 32 & 7.4 \\
\hline Catholic & 469 & 29.7 & 36 & 8.7 & 34 & 8.3 \\
\hline Other & 114 & 7.2 & 9 & 9.5 & 7 & 7.4 \\
\hline None & 493 & 31.2 & 32 & 7.7 & 36 & 8.7 \\
\hline \multicolumn{7}{|l|}{ Belong to a community of faith } \\
\hline Yes & 471 & 29.8 & 28 & 6.9 & 31 & 7.6 \\
\hline No & 1109 & 70.2 & 72 & 7.6 & 78 & 8.3 \\
\hline \multicolumn{7}{|l|}{ Believing } \\
\hline Yes & 882 & 55.8 & 83 & 10.6 & 69 & 8.8 \\
\hline No & 698 & 44.2 & 17 & 3.0 & 40 & 7.0 \\
\hline \multicolumn{7}{|l|}{ Self-reported diagnosis - self } \\
\hline Yes & 225 & 16.1 & 27 & 11.3 & 71 & 29.7 \\
\hline No & 1275 & 80.7 & 69 & 6.5 & 34 & 3.2 \\
\hline No answer & 50 & 3.2 & 4 & 8.9 & 4 & 8.9 \\
\hline
\end{tabular}

\begin{tabular}{|c|c|c|c|c|c|c|}
\hline & \multicolumn{2}{|c|}{ Total } & \multicolumn{2}{|c|}{ Healer } & \multicolumn{2}{|c|}{ Psychiatrist } \\
\hline & $N$ & $\%$ & $N$ & $\%$ & $N$ & $\%$ \\
\hline \multicolumn{7}{|c|}{ Self-reported diagnosis - family } \\
\hline Yes & 350 & 22.2 & 24 & 7.5 & 37 & 11.5 \\
\hline No & 1169 & 74.0 & 75 & 7.7 & 64 & 6.5 \\
\hline No answer & 61 & 3.9 & 1 & 1.9 & 8 & 15.4 \\
\hline \multicolumn{7}{|l|}{$\mathrm{Ml}$} \\
\hline Skeptics & 827 & 52.3 & 11 & 1.7 & 34 & 5.3 \\
\hline Believers & 753 & 47.7 & 89 & 12.5 & 75 & 10.5 \\
\hline
\end{tabular}

Within a category, bolded figures are significantly different at $p<0.05$, according to Chi-square tests.

\section{CONNECTION MENTAL DISORDER - EE - HELP-SEEKING}

The frequency of EE (91\%) and self-reported mental disorder $(16 \%)$ in the examined population is comparable with other studies $(1,2,38)$. Therefore, $\mathrm{EE}$ are too frequent to be an unequivocal indicator of a mental disorder. The subjective burden that might lead one to seek help is according to psychopathology not indicative of the differentiation between illness and health. Whether this is the case in EE remains to be determined. However, it has been shown that if EE are successfully coped with, they can add to psychological health (3). Help-seeking in general is more frequent when experiences are of rather negative valence. It has been shown that the valence of $\mathrm{EE}$ also determines whether experiences could contribute to mental health (3). Therefore, helping persons to integrate their experiences and assign meaning to them, which should lead to a more positive valence $(37,39)$, might not only be beneficial in the case of (comorbid) mental disorder but also for healthy individuals. When persons with such a diagnosis - and also their assistants - automatically subsume EE under the symptoms of that disorder, they might miss these positive coping strategies. As Belz-Merk and Fach (3) have stated, the mental health care system might not be entirely adequate for persons with EE. If this is the case, an adaptation might be necessary to optimally help people with EE, especially those without concomitant mental disorder. It is important that the mental health system meets needs of people with EE because firstly, many of them seek help from the mental health care system, and secondly, because there is some evidence that a therapy tailored to enhance coping with EE could be beneficial for people with and without mental disorder.

\section{HELP-SEEKING AND SELF-REPORTED MENTAL DISORDER}

Our data indicate that people suffering from EE but without self-reported mental disorder less often sought help even when attributes of EE, including the frequency and valence, were controlled for. We do not know whether persons without self-reported mental disorder do require less help to cope with their EE than persons with a disorder. It cannot be determined from our data whether persons who seek help suffer from prodromal or initial psychiatric disorders. We explain the lower rates of help-seeking by a higher threshold to seek help from the mental health care system in persons without mental disorder. Possibly one aspect of the 
Table 3 | Continuous predictors of lifetime help-seeking because of EE ( $N$ depending on predictors and help-seeking variables).

\begin{tabular}{|c|c|c|c|c|c|c|c|c|c|c|}
\hline & \multicolumn{2}{|c|}{ Total } & \multicolumn{4}{|c|}{ Healer } & \multicolumn{4}{|c|}{ Psychiatrist } \\
\hline & \multirow[b]{2}{*}{$N$} & \multirow[b]{2}{*}{ Mean } & \multicolumn{2}{|c|}{ Yes } & \multicolumn{2}{|c|}{ No } & \multicolumn{2}{|c|}{ Yes } & \multicolumn{2}{|c|}{ No } \\
\hline & & & $N$ & Mean & $N$ & Mean & $N$ & Mean & $N$ & Mean \\
\hline Age & 1580 & 39.09 & 100 & 39.80 & 1253 & 38.81 & 109 & 40.81 & 1244 & 38.71 \\
\hline PAGE-R external phenomenon (mean) & 1173 & 0.76 & 100 & 1.37 & 1041 & 0.71 & 100 & 0.82 & 1041 & 0.62 \\
\hline PAGE-R internal phenomenon (mean) & 1165 & 0.76 & 98 & 1.38 & 1021 & 0.73 & 101 & 0.81 & 1018 & 0.61 \\
\hline PAGE-R phenomenon of coincidence (mean) & 1291 & 0.96 & 99 & 1.73 & 1141 & 0.92 & 103 & 0.83 & 1137 & 0.72 \\
\hline PAGE-R psychophysical dissociation (mean) & 776 & 0.55 & 88 & 0.96 & 663 & 0.51 & 87 & 0.71 & 664 & 0.55 \\
\hline PAGE-R induced by spiritual techniques & 1353 & 0.58 & 100 & 1.40 & 1253 & 0.51 & 109 & 0.95 & 1244 & 0.55 \\
\hline PAGE-R negative valence & 1353 & 0.81 & 100 & 1.25 & 1253 & 0.77 & 109 & 1.55 & 1244 & 0.74 \\
\hline PAGE-R spontaneous, positive valence & 1353 & 1.53 & 100 & 1.94 & 1253 & 1.50 & 109 & 1.67 & 1244 & 1.52 \\
\hline PAGE-R density (mean) & 1439 & 1.14 & 100 & 1.74 & 1253 & 1.17 & 109 & 1.44 & 1244 & 1.20 \\
\hline PAGE-R impact (mean) & 1439 & 0.80 & 100 & 1.92 & 1253 & 0.76 & 109 & 1.31 & 1244 & 0.81 \\
\hline MI (mean) & 1580 & 0.32 & 100 & 0.51 & 1253 & 0.33 & 109 & 0.42 & 1244 & 0.33 \\
\hline
\end{tabular}

Within a category, bolded figures are significantly different at $p<0.05$, according to $t$-tests.

high threshold is that it is difficult to approach that system without declaring oneself as mentally ill. Whether there is an unmet medical need in mentally healthy persons with EE or whether there is an alternative explanation for the lower rates of help-seeking should be confirmed by further research, especially longitudinal studies assessing EE, mental disorder, the degree of suffering, and concomitant factors as resilience, coping, and help-seeking are needed.

The higher rate of help-seeking in persons with (a history of) self-reported mental disorder is possibly explained by the a priori involvement that persons suffering from mental disorder had with the mental health treatment system. Because their confidants are already mental health professionals, those contacts are then re-activated because of EE. A second possibility is that those with a self-reported diagnosis of mental disorder have another system of beliefs to explain feelings and perceptions they do not understand at first sight drawing on a "disease" model. This hypothesis parallels the supposition that those without a self-reported mental disorder but seeking help from a healer have a spiritual view of EE. The third explanation for the higher rate of help-seeking is that persons who sought help had a higher level of subjective distress, which was not assessed by the questionnaires used in this study.

\section{OTHER PREDICTORS OF HELP-SEEKING}

In our combined model, socio-demographical predictors were gender, education, and occupation. Women with lower education, being a believer rather than a skeptic according to the MI, and describing themselves as believing in some deity, more often sought help from a healer alone because of EE. Gender has been associated quite consistently with help-seeking in persons with mental disorders, with women having higher treatment rates (24). In contrast, our data indicated that gender modulated the choice of assistant, with women visiting a psychiatrist less often than men. That women with less education visited more often healers than other sources of help indicates a higher acceptance of healers. Whether this implies any risk remains to be determined.
Our results are in line with other fields of research that show a therapeutic undersupply of women (40). Interestingly, men who described themselves as pensioners or benefit recipients belonged to the group of people who visited both a healer and a mental health professional. However, this result can be misleading because the question about occupation did not assess unemployment. Therefore, we do not know whether unemployed persons selected "homework" or "pensioner, receiving benefit" as their occupational status. In the previous IGPP study on help-seeking, persons having contact with psychiatry were $48 \%$ male, and $63 \%$ were not working (3). Unfortunately, our cross-sectional data did not allow us to disentangle further the causal interrelations among mental health status, occupation, gender, and EE.

Another interesting predictor of help-seeking was MI. Importantly, EE and MI are not the same. Persons may highly believe in the paranormal without having the respective experiences, and highly skeptical persons may experience things they do not believe in. In this study, skeptics were less inclined to seek help from a healer alone, even if EE were controlled for. This finding supports the hypothesis that systems of belief guide the choice of the helping agent.

In general, negative valence of EE was associated with helpseeking. When EE had more impact (i.e., higher scores on the item "How much are you concerning yourself with your experiences up to now?"), persons preferred seeing a healer or both sources of help. The involvement of a healer could be explained that persons who were more focused on their EE sought for an explanation that a professional psychotherapy was not able to give. Another predictor for help-seeking from a healer or both sources was the trigger of EE, e.g., the experiences were induced by spiritual techniques. Therefore, persons already familiar with esoteric practices were more prepared to seek help within their corresponding system of belief. Exceptional experiences can be triggered in manifold ways: Often they follow a crisis situation or an event such as death within an individual's environment. But they can also occur in association with altered states of consciousness either during the transition 
Table 4 | Multinomial regression with predictors of help-seeking because of EE.

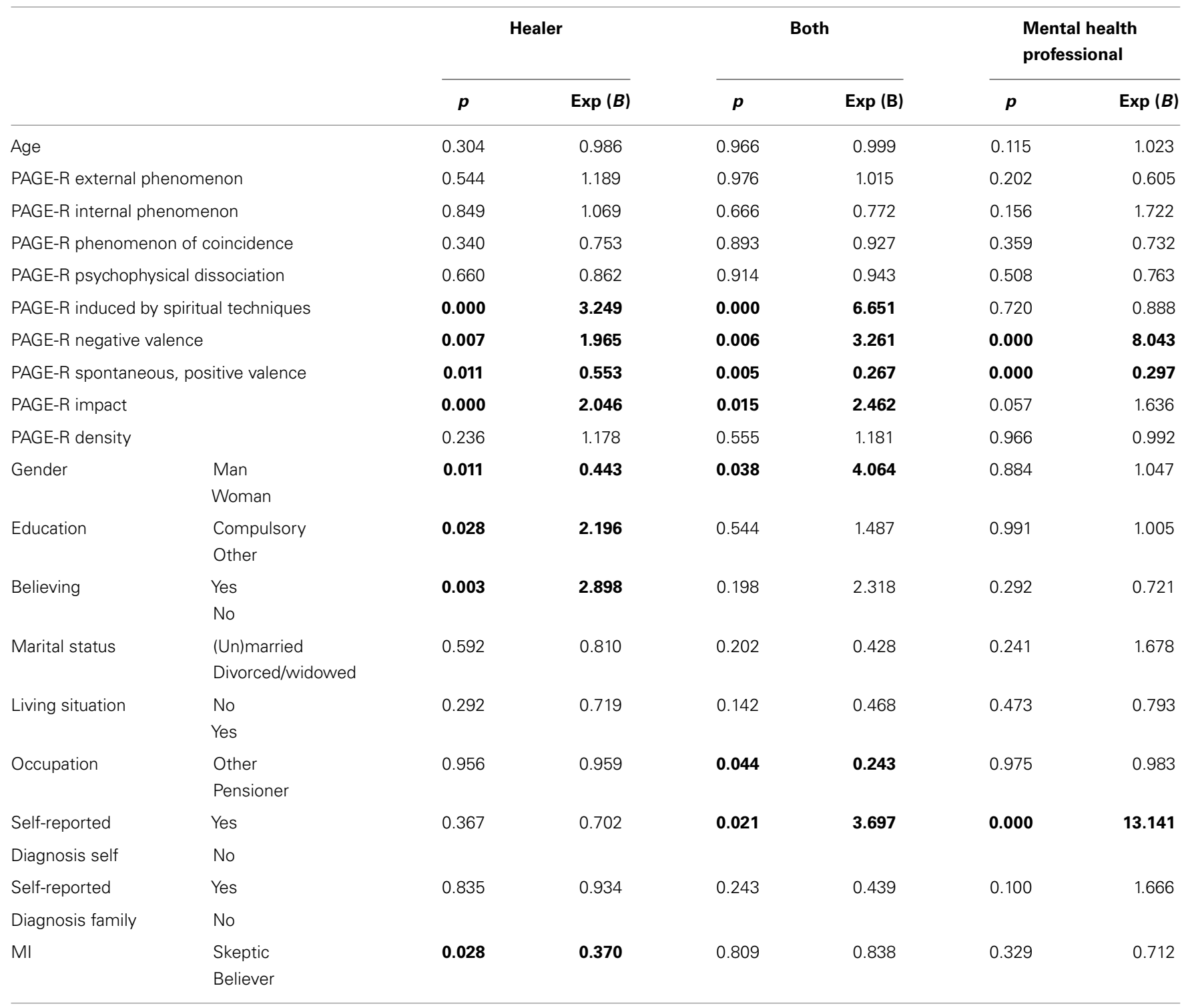

Dependent variable $=$ healer/mental health professional/both/none (reference). $N=1270$ for sample of participants who answered the questions concerning helpseeking and psychiatric diagnoses. Within a category, bolded figures are significant at $p<0.05$. Pseudo R-square: Cox and Snell $=0.312$, Nagelkerke $=0.480$, McFadden $=0.316$.

between wakefulness and sleep or when induced by psychotropic drugs. Other stimulating situations include involvement in meditation, spiritual, occult or magical practices; contact with healers, shamans, or mediums; or intense psychotherapy or psychoanalysis. Therefore, it remains unclear whether the contact with healers triggered the EE, or whether people activated previous contacts to healers to discuss their EE.

\section{CONCLUSION}

Our results indicate that persons with EE who do not suffer from self-reported mental disorder less often sought help because of EE. We attributed this to a high inhibition threshold for people without a history of self-reported mental disorder to seek professional help. Especially, less educated women did not approach the mental health care system as often as other persons with EE, but preferred seeing a healer. There are some hints that an adequate therapy might be beneficial in the case of EE. Whether not seeking help or preferring a healer is of negative consequences remains to be determined. The higher rate of help-seeking from the mental health care system in persons with acute or previous mental disorder leads to the assumption that either pre-existing contact, or the dominant system of belief of the person, led help-seeking. A parallel preference for healers in persons with a spiritual worldview supports this interpretation. Whether subjective distress also led to higher rates of help-seeking remains to be determined. 
Table 5 | Logistic regression including characteristics of EE

\begin{tabular}{|c|c|c|c|c|c|c|}
\hline & $B$ & SD & Wald & df & $p$ & $\operatorname{Exp}(B)$ \\
\hline $\begin{array}{l}\text { Diagnosis of mental } \\
\text { disorder (yes) }\end{array}$ & 1.493 & 0.207 & 52.136 & 1 & 0.000 & 4.452 \\
\hline PAGE-R number of EE & 0.066 & 0.027 & 6.152 & 1 & 0.013 & 1.068 \\
\hline $\begin{array}{l}\text { PAGE-R mean } \\
\text { frequency of } E E\end{array}$ & -1.134 & 0.411 & 7.636 & 1 & 0.006 & 0.322 \\
\hline $\begin{array}{l}\text { PAGE-R induced by } \\
\text { spiritual techniques }\end{array}$ & 0.110 & 0.027 & 16.131 & 1 & 0.000 & 1.117 \\
\hline $\begin{array}{l}\text { PAGE-R negative } \\
\text { valence }\end{array}$ & 0.166 & 0.024 & 47.482 & 1 & 0.000 & 1.180 \\
\hline $\begin{array}{l}\text { PAGE-R spontaneous, } \\
\text { positive valence }\end{array}$ & -0.222 & 0.038 & 34.098 & 1 & 0.000 & 0.801 \\
\hline PAGE-R impact & 0.921 & 0.144 & 40.928 & 1 & 0.000 & 2.513 \\
\hline $\begin{array}{l}\text { PAGE-R density over } \\
\text { life course }\end{array}$ & 0.091 & 0.103 & 0.785 & 1 & 0.376 & 1.096 \\
\hline
\end{tabular}

This regression illustrates that persons with a self-reported diagnosis of a mental disorder seek more often help than those without, controlling for all possible char acteristics of EE. $N=1308$ for sample without missing values. Pseudo R-square: Cox and Snell=0.203, Nagelkerke $=0.371$.

\section{LIMITATIONS}

It remains to be verified whether the mental health care system meets the needs of persons with EE or whether a special treatment system might be required, as Belz-Merk and Fach (3) suggested.

It is unclear how the readiness of individuals to reveal EE can be faithfully assessed. Although there may be considerable openness for experiences and the willingness to admit them by the general population, a tendency to rationalize those experiences and include narrative caveats in official reports can invite caution (1).

The sample we used represented the Swiss general population based only upon gender, age, and level of education. Even if the total sample size was considerable, cell sizes of statistical analyses sometimes were small, so the detailed results need confirmation by additional studies. Diagnoses of mental disorder were assessed by directly asking the respondents, but were not verified through a diagnostic interview. The questions did not determine whether the reported EE had occurred unequivocally as a symptom of a mental disorder. Diagnoses, EE, and help-seeking behavior were assessed according to lifetime prevalence. Therefore, association could not implicate contemporaneity. While the PAGE-R assessing EE was quite comprehensive, the MI covered only a small fraction of their overall spectrum.

\section{AUTHOR CONTRIBUTIONS}

Karin Landolt analyzed and interpreted the data and drafted the manuscript. Amrei Wittwer contributed to the study design, interpreted the data, and drafted the manuscript. Thomas Wyss and Lui Unterassner contributed to the study design and the acquisition of data and revised the manuscript critically. Wolfgang Fach contributed to the conception and design of the study and was involved in drafting the manuscript. Peter Krummenacher, Peter Brugger, Helene Haker, Wolfram Kawohl, Pius August
Schubiger, Gerd Folkers, and Wulf Rössler contributed to the conception and design of the study and revised the manuscript critically. All authors have given final approval for the version to be published and agreed to be accountable for all aspects of the work.

\section{ACKNOWLEDGMENTS}

We thank Harald Atmanspacher for the very helpful discussions and Richard Dähler for the careful and precise lectorat.

\section{REFERENCES}

1. Schmied-Knittel I, Schetsche M. Everyday miracles: results of a representative survey in Germany. Eur J Parapsychol (2005) 20:3-21.

2. Haraldsson E, Houtkooper J. Psychic experiences in the multi-national human values study. J Am Soc Psych Res (1991) 85(2):145-65.

3. Belz-Merk M, Fach W. Help and advice for people with exceptional experiences. Psychother Psychosom Med Psychol (2005) 55(5):256-65. doi:10.1055/s-2004834682

4. Peters E, Day S, McKenna J, Orbach G. Delusional ideation in religious and psychotic populations. Br J Clin Psychol (1999) 38(Pt 1):83-96. doi:10.1348/ 014466599162683 Epub 1999/04/23.

5. Brugger P, Graves RE. Testing vs. believing hypotheses: magical ideation in the judgment of contingencies. Cogn Neuropsychiatry (1997) 2(4):251-72. doi:10.1080/135468097396270

6. Metzinger T. Being No One: The Self-Model Theory of Subjectivity. Cambridge: MIT Press (2003).

7. Belz M, Fach W. Theoretical reflections of counseling and therapy for individuals reporting ExE (exceptional experiences). In: Kramer WH, Bauer E, Hövelmann GH, editors. Perspectives of Clinical Parapsychology. Bunning: Stichting Het Johan Borgman Fonds (2012). p. 168-89.

8. Fach W. Phenomenological aspects of complementarity and entanglement in exceptional human experiences (ExE). Axiomathes (2011) 21:233-47. doi:10. 1007/s10516-010-9143-7

9. Eckblad M, Chapman LJ. Magical ideation as an indicator of schizotypy. J Consult Clin Psychol (1983) 51(2):215-25. doi:10.1037/0022-006X.51.2.215

10. Lindeman M, Aarnio K. Paranormal beliefs: their dimensionality and correlates. Eur J Pers (2006) 20(7):585-602. doi:10.1002/per.608

11. Johns LC, van Os J. The continuity of psychotic experiences in the general population. Clin Psychol Rev (2001) 21(8):1125-41. doi:10.1016/S0272-7358(01) 00103-9

12. van Os J, Linscott RJ, Myin-Germeys I, Delespaul P, Krabbendam L. A systematic review and meta-analysis of the psychosis continuum: evidence for a psychosis proneness-persistence-impairment model of psychotic disorder. Psychol Med (2009) 39(2):179-95. doi:10.1017/S0033291708003814

13. Rössler W, Riecher-Rossler A, Angst J, Murray R, Gamma A, Eich D, et al. Psychotic experiences in the general population: a twenty-year prospective community study. Schizophr Res (2007) 92(1-3):1-14. doi:10.1016/j.schres.2007.01.002

14. Berenbaum H, Kerns J, Raghavan C. Anomalous experiences, peculiarity, and psychopathology. In: Cardeña E, Lynn SJ, Krippner S, editors. Varieties of Anomalous Experience: Examining the Scientific Evidence. Washington, DC: American Psychological Association (2000). p. 25-46.

15. Thalbourne M, Delin P. A common thread underlying belief in the paranormal, creative personality, mystical experience and psychopathology. J Parapsychol (1994) 58(3):3-38.

16. Davidson M, Keefe RS, Mohs RC, Siever LJ, Losonczy MF, Horvath TB, et al. L-dopa challenge and relapse in schizophrenia. Am J Psychiatry (1987) 144(7):934-8.

17. Davidson M, Davis KL. A comparison of plasma homovanillic acid concentrations in schizophrenic patients and normal controls. Arch Gen Psychiatry (1988) 45(6):561-3. doi:10.1001/archpsyc.1988.01800300057006

18. Siever LJ, Amin F, Coccaro EF, Trestman R, Silverman J, Horvath TB, et al. CSF homovanillic acid in schizotypal personality disorder. Am J Psychiatry (1993) 150(1):149-51.

19. Huttunen J, Heinimaa M, Svirskis T, Nyman M, Kajander J, Forsback S, et al. Striatal dopamine synthesis in first-degree relatives of patients with schizophrenia. Biol Psychiatry (2008) 63(1):114-7. doi:10.1016/j.biopsych.2007.04.017 
20. Howes OD, Kapur S. The dopamine hypothesis of schizophrenia: version III the final common pathway. Schizophr Bull (2009) 35(3):549-62. doi:10.1093/ schbul/sbp006

21. Krummenacher P, Mohr C, Haker H, Brugger P. Dopamine, paranormal belief, and the detection of meaningful stimuli. J Cogn Neurosci (2009) 22(8):1670-81. doi:10.1162/jocn.2009.21313

22. Hellmeister G, Fach W. Anbieter und Verbraucher auf dem Psychomarkt. Eine empirische Analyse. In: Bundestag D, editor. Neue Religiöse und Ideologische Gemeinschaften und Psychogruppen. Hamm: Hoheneck (1998). p. 356-99.

23. Regier DA, Narrow WE, Rae DS, Manderscheid RW, Locke BZ, Goodwin FK. The de facto US mental and addictive disorders service system. Epidemiologic catchment area prospective 1-year prevalence rates of disorders and services. Arch Gen Psychiatry (1993) 50(2):85-94. doi:10.1001/archpsyc.1993. 01820140007001

24. Wang PS, Lane M, Olfson M, Pincus HA, Wells KB, Kessler RC. Twelve-month use of mental health services in the United States: results from the national comorbidity survey replication. Arch Gen Psychiatry (2005) 62(6):629-40. doi:10.1001/archpsyc.62.6.629

25. Wittchen HU, Jacobi F, Rehm J, Gustavsson A, Svensson M, Jonsson B, et al. The size and burden of mental disorders and other disorders of the brain in Europe 2010. Eur Neuropsychopharmacol (2011) 21(9):655-79. doi:10.1016/j. euroneuro.2011.07.018

26. Angst J, Gamma A, Clarke D, Ajdacic-Gross V, Rossler W, Regier D. Subjective distress predicts treatment seeking for depression, bipolar, anxiety, panic, neurasthenia and insomnia severity spectra. Acta Psychiatr Scand (2010) 122(6):488-98. doi:10.1111/j.1600-0447.2010.01580.x

27. Fach W, Lehmann V. Abteilung Beratung und Information des IGPP. Revidierter Fragebogen zur Erfassung der Phänomenologie Aussergewöhnlicher Erfahrungen (PAGE-R). Freiburg: Unveröffentlichter Fragebogen, Institut für Grenzgebiete der Psychologie und Psychohygiene e.V. (IGPP) (2011).

28. Lehmann V. Entwicklung eines Fragebogens zur Erfassung der Phänomenologie Aussergewöhnlicher Erfahrungen (PAGE). Freiburg: Unveröffentlichte Diplomarbeit, Albert-Ludwigs-Universität Freiburg (2008).

29. Fach W, Atmanspacher H, Landolt K, Wyss T, Rössler W. A comparative study of exceptional experiences of clients seeking advice and subjects in an ordinary population. Front Psychol (2013) 4:65. doi:10.3389/fpsyg.2013.00065

30. Bauer E, Belz M, Fach W, Fangmeier R, Schupp-Ihle C, Wiedemer A. Counseling at the IGPP - an overview. In: Kramer WH, Bauer E, Hövelmann GH, editors. Perspectives of Clinical Parapsychology. Bunnik: Stichting Het Johan Borgman Fonds (2012). p. 149-67.

31. Schmeidler G. Predicting good and bad scores in a clairvoyance experiment: a final report. J Am Soc Psych Res (1943) 37:210-21.

32. Brugger P, Landis T, Regard M. A “sheep-goat” effect in repetition avoidance: extra-sensory perception as an effect of subjective probability? $\mathrm{Br} J$ Psychol (1990) 81:455-68. doi:10.1111/j.2044-8295.1990.tb02372.x
33. Hadlaczky G, Westerlund J. Sensitivity to coincidences and paranormal belief. Percept Mot Skills (2011) 113(3):894-908. doi:10.2466/09.22.PMS.113. 6.894-908

34. Gianotti LR, Mohr C, Pizzagalli D, Lehmann D, Brugger P. Associative processing and paranormal belief. Psychiatry Clin Neurosci (2001) 55(6):595-603. doi:10.1046/j.1440-1819.2001.00911.x

35. Mohr C, Landis T, Brugger P. Lateralized semantic priming: modulation by levodopa, semantic distance, and participants' magical beliefs. Neuropsychiatr Dis Treat (2006) 2(1):71-84.

36. Reed P, Wakefield D, Harris J, Parry J, Cella M, Tsakanikos E. Seeing nonexistent events: effects of environmental conditions, schizotypal symptoms, and sub-clinical characteristics. J Behav Ther Exp Psychiatry (2008) 39(3):276-91. doi:10.1016/j.jbtep.2007.07.005

37. Belz M. Außergewöhnliche Erfahrungen. Göttingen: Hogrefe-Verlag (2009).

38. Angst J, Gamma A, Neuenschwander M, Ajdacic-Gross V, Eich D, Rossler W, et al. Prevalence of mental disorders in the Zurich Cohort Study: a twenty year prospective study. Epidemiol Psichiatr Soc (2005) 14(2):68-76. doi:10.1017/ S1121189X00006278

39. Kohls NB. Aussergewöhnliche Erfahrungen-Blinder Fleck in der Psychologie? Eine Auseinandersetzung mit Aussergewöhnlichen Erfahrungen und Ihrem Zusammenhang mit Geistiger Gesundheit. Münster: LIT Verlag (2004).

40. Hoffmann DE, Tarzian AJ. The girl who cried pain: a bias against women in the treatment of pain. J Law Med Ethics (2001) 29(1):13-27. doi:10.1111/j.1748720X.2001.tb00037.x

Conflict of Interest Statement: The Associate Editor Alexandre Andrade Loch declares that, despite being affiliated to the same institution as author Wulf Rössler, the review process was handled objectively and no conflict of interest exists. The authors declare that the research was conducted in the absence of any commercial or financial relationships that could be construed as a potential conflict of interest.

Received: 12 March 2014; accepted: 07 May 2014; published online: 21 May 2014. Citation: Landolt K, Wittwer A, Wyss T, Unterassner L, Fach W, Krummenacher P, Brugger P, Haker H, Kawohl W, Schubiger PA, Folkers G and Rössler W (2014) Help-seeking in people with exceptional experiences: results from a general population sample. Front. Public Health 2:51. doi: 10.3389/fpubh.2014.00051

This article was submitted to Public Mental Health, a section of the journal Frontiers in Public Health.

Copyright (c) 2014 Landolt, Wittwer, Wyss, Unterassner, Fach, Krummenacher, Brugger, Haker, Kawohl, Schubiger, Folkers and Rössler. This is an open-access article distributed under the terms of the Creative Commons Attribution License (CC BY). The use, distribution or reproduction in other forums is permitted, provided the original author(s) or licensor are credited and that the original publication in this journal is cited, in accordance with accepted academic practice. No use, distribution or reproduction is permitted which does not comply with these terms. 